\title{
Article
}

\section{Cigarette Smoking, miR-27b Downregulation, and Peripheral Artery Disease: Insights into the Mechanisms of Smoking Toxicity}

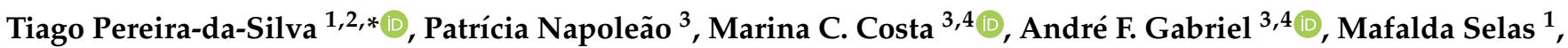 \\ Filipa Silva ${ }^{1}$, Francisco J. Enguita ${ }^{3,4}{ }^{\mathbb{D}}$, Rui Cruz Ferreira ${ }^{1}$ and Miguel Mota Carmo ${ }^{5}$ (i) \\ 1 Department of Cardiology, Hospital de Santa Marta, Centro Hospitalar Universitário de Lisboa Central, \\ 1169-024 Lisbon, Portugal; mafalda.selas@gmail.com (M.S.); felipafernandes@gmail.com (F.S.); \\ cruzferreira@netcabo.pt (R.C.F.) \\ 2 NOVA Doctoral School, NOVA Medical School I Faculdade de Ciências Médicas, \\ Universidade NOVA de Lisboa, 1169-056 Lisbon, Portugal \\ 3 Instituto de Medicina Molecular João Lobo Antunes, Faculdade de Medicina, Universidade de Lisboa, \\ 1649-028 Lisbon, Portugal; napoleao.patricia@gmail.com (P.N.); marinacosta@medicina.ulisboa.pt (M.C.C.); \\ andre.gabriel@medicina.ulisboa.pt (A.F.G.); fenguita@medicina.ulisboa.pt (F.J.E.) \\ 4 Cardiomics Unit, Centro Cardiovascular da Universidade de Lisboa, Faculdade de Medicina, \\ Universidade de Lisboa, 1649-028 Lisbon, Portugal \\ 5 Chronic Diseases Research Center (CEDOC), NOVA Medical School, Faculdade de Ciências Médicas, \\ Universidade NOVA de Lisboa, 1150-082 Lisbon, Portugal; mabmc@sapo.pt \\ * Correspondence: tiagopsilva@sapo.pt; Tel.: +351-919908505
}

Citation: Pereira-da-Silva, T.; Napoleão, P.; Costa, M.C.; Gabriel, A.F.; Selas, M.; Silva, F.; Enguita, F.J.; Ferreira, R.C.; Carmo, M.M. Cigarette Smoking, miR-27b Downregulation, and Peripheral Artery Disease: Insights into the Mechanisms of Smoking Toxicity. J. Clin. Med. 2021, 10, 890. https://doi.org/10.3390/jcm10040890

Academic Editor:

Anna Kabłak-Ziembicka

Received: 5 January 2021

Accepted: 17 February 2021

Published: 22 February 2021

Publisher's Note: MDPI stays neutral with regard to jurisdictional claims in published maps and institutional affiliations.

Copyright: (c) 2021 by the authors. Licensee MDPI, Basel, Switzerland. This article is an open access article distributed under the terms and conditions of the Creative Commons Attribution (CC BY) license (https:// creativecommons.org/licenses/by/ $4.0 /)$.

\begin{abstract}
Cigarette smoking is a risk factor for the development of peripheral artery disease (PAD), although the proatherosclerotic mediators of cigarette smoking are not entirely known. We explored whether circulating microRNAs (miRNAs) are dysregulated in cigarette smokers and associated with the presence of PAD. Ninety-four participants were recruited, including 58 individuals without and 36 with PAD, 51 never smokers, 28 prior smokers, and 15 active smokers. The relative expression of six circulating miRNAs with distinct biological roles (miR-21, miR-27b, miR-29a, miR-126, miR-146, and miR-218) was assessed. Cigarette smoking was associated with the presence of PAD in multivariate analysis. Active smokers, but not prior smokers, presented miR-27b downregulation and higher leukocyte, neutrophil, and lymphocyte counts; miR-27b expression levels were independently associated with active smoking. Considering the metabolic and/or inflammatory abnormalities induced by cigarette smoking, miR-27b was independently associated with the presence of PAD and downregulated in patients with more extensive PAD. In conclusion, the atheroprotective miR-27b was downregulated in active smokers, but not in prior smokers, and miR-27b expression was independently associated with the presence of PAD. These unreported data suggest that the proatherogenic properties of cigarette smoking are mediated by a downregulation of miR-27b, which may be attenuated by smoking cessation.
\end{abstract}

Keywords: atherosclerosis; cigarette smoking; miR-27b; peripheral artery disease

\section{Introduction}

Cigarette smoking is a major health hazard, being accountable for substantial cardiovascular morbidity and mortality worldwide due to its proatherogenic effects [1] Cigarette smoking increases the risk of atherosclerosis development by several fold and is a more influential risk factor for peripheral artery disease (PAD) than for atherosclerosis of other territories, including coronary arteries [2]. Some of the mechanisms associated with cigarette-smoking-induced atherogenesis include the activation of inflammation, dysregulation of the lipid metabolism, increase in oxidative stress, and endothelial dysfunction $[1,2]$. Nevertheless, the pathophysiology associated with the initiation and progression of atherosclerosis secondary to cigarette smoking is not entirely known $[1,2]$. 
MicroRNAs (miRNAs) are small noncoding RNA molecules that regulate the genetic expression at the post-transcriptional level [3]. Cigarette smoking is associated with an altered expression of circulating miRNAs, including an upregulation of pro-inflammatory miRNAs $[4,5]$. On the other hand, specific miRNAs participate in different steps of atherogenesis, and a dysregulated expression of circulating miRNAs was described in patients with stable atherosclerosis of different territories [3,6]. However, to the best of our knowledge, coexistent associations among cigarette smoking, miRNA dysregulation, and the presence of atherosclerosis in humans have not been reported. The identification of miRNA dysregulation in association with both cigarette smoking and atherosclerosis could provide insights into the pathophysiology of cigarette-smoking toxicity. In fact, miRNAs may mediate the causal relationship between cigarette smoking and atherosclerosis development, especially PAD, which is particularly influenced by cigarette smoking [2].

Of the diversity of miRNAs associated with atherosclerosis regulation, $\mathrm{miR}-27 \mathrm{~b}, \mathrm{miR}-$ 21, miR-29a, miR-126, miR-146, and miR-218 participate in distinct pathways and/or have distinct mechanisms of action, as described in experimental models, and were also reported to be dysregulated in patients with stable atherosclerosis [3,6-9]. Of note, miR-27b is a pleiotropic miRNA, and its expression is associated not only with atherosclerotic disease but also with non-atherosclerotic cardiovascular processes, such as cardiomyocyte hypertrophy and non-cardiovascular diseases, including cancer, non-alcoholic fatty liver disease, and viral infections [10-18]. Specifically, regarding atherosclerosis, miR-27b regulates lipid metabolism, development of lipid-induced atherosclerotic lesions, vascular inflammation, endothelial function, and angiogenesis [19-26]. Overall, the reported effects of miR-27b in experimental models are atheroprotective [19-26]. Among the relevant roles of the remaining miRNAs in the development and expression of atherosclerosis, miR-21 regulates vascular smooth cell and endothelial cell functions, miR-29a regulates fibrosis and extracellular matrix composition, miR-126 regulates endothelial function in response to shear stress, miR-146 regulates endothelial function in response to inflammatory cytokines, and $\mathrm{miR}-218$ regulates endothelial cell migration $[3,7,8]$.

We explored whether circulating miRNAs are simultaneously dysregulated in cigarette smokers and associated with the presence of PAD.

\section{Materials and Methods}

The study protocol was approved by the ethics committees of the involved institutions (Centro Hospitalar Universitário de Lisboa Central, Nr. 245/2015, in 2015, and the NOVA Medical School I Faculdade de Ciências Médicas, Universidade NOVA de Lisboa, Nr. 000176, in 2015). The investigation conformed to the principles outlined in the Helsinki Declaration. All the participants signed informed consent forms.

\subsection{Recruitment of Participants}

Two groups of participants from our center were recruited, with and without PAD. PAD was defined as a significant $(\geq 50 \%)$ stenosis on Doppler ultrasound at rest $[27,28]$ or the combination of chronic claudication and an ankle-brachial index equal to or less than $0.9[28,29]$. Doppler ultrasound was performed for the characterization of PAD, according to a standardized protocol, using the GE Logiq S7 Expert Ultrasound System, and measurements were performed while following published guidelines [28,29].

We excluded patients with critical limb ischemia (with ischemic rest pain), those with acute ischemic events within 12 months in any arterial territory, those with lower-extremity bypass surgery performed within 12 months, those with any prior percutaneous arterial treatment, those with heart failure, hemodynamically significant valvular heart disease, hematological disorders, active infection (based on symptoms and/or signs, including fever, and leukocyte count, white blood cell differential, and C-reactive protein levels), history of malignancy, chronic kidney disease (stage 4 or 5), or severe hepatic dysfunction, those under 18 years of age, and those unable or unwilling to consent to study participation. 


\subsection{Data Collection}

Data were collected prospectively after patient inclusion. A standardized record including clinical, demographic, laboratory, echocardiographic, and Doppler ultrasound data was obtained from each participant. Participants were classified according to cigarettesmoking status as never smokers, prior smokers (if cessation occurred at least six months before), or active smokers (in cases of daily cigarette smoking, irrespective of the number of cigarettes) [30].

\subsection{Candidate miRNAs}

Six candidate miRNAs (miR-21, miR-27b, miR-29a, miR-126, miR-146, and miR-218) were selected based on the following criteria: miRNAs are associated with the regulation of atherosclerosis development and expression in experimental models $[3,7,8]$; each of the miRNAs regulates distinct pathways of atherosclerotic disease and/or has distinct mechanisms of action $[3,7,8]$; miRNAs were reported to be dysregulated in patients with stable atherosclerosis $[6,9]$.

\subsection{Quantification of Expression Levels of Candidate miRNAs}

Peripheral blood was collected early in the morning under fasting conditions. Serum was separated by centrifugation $(500 \times g$ for $10 \mathrm{~min}$ ) within $15 \mathrm{~min}$ of sampling. Aliquots were stored at $-80^{\circ} \mathrm{C}$, and samples were thawed only once.

Total RNA was extracted from serum samples using the miRCURYTM RNA Isolation Kit (Qiagen, Hilden, Germany). Complementary DNA was synthesized from total RNA using the Universal complementary DNA (cDNA) synthesis kit from the miRCURYTM LNA miRNA system (Qiagen, Hilden, Germany). miRNA amplification was performed using quantitative reverse-transcription polymerase chain reaction (using the miRCURY ${ }^{\mathrm{TM}}$ LNA SYBR Green PCR Kit and LNA ${ }^{\mathrm{TM}}$ PCR primers, Qiagen, Hilden, Germany), and the melting curve was determined according to the following conditions: $95^{\circ} \mathrm{C}$ for $10 \mathrm{~min}$, followed by 45 cycles of $95^{\circ} \mathrm{C}$ for $10 \mathrm{~s}$ and $60^{\circ} \mathrm{C}$ for $60 \mathrm{~s}$. All reactions were performed in triplicate. The amplification data were assessed using DataAssist ${ }^{\mathrm{TM}}$ Software v3.01. Cycle threshold $(\mathrm{Ct})$ values greater than 40 were considered undetermined [31-34]. The relative expression levels of the six candidate miRNAs were calculated using the delta $\mathrm{Ct}(\Delta \mathrm{Ct})$ method, normalizing for the UniSp6 RNA spike-in control [34-37]. Higher $\Delta \mathrm{Ct}$ miRs represent lower circulating levels of the candidate miRNAs [34-37]. Where appropriate, the fold-change in the miRNA expression levels was expressed using the Livak method $\left(2^{-\Delta \Delta C t}\right)$ [38].

\subsection{Statistical Analysis}

Discrete variables are presented as frequencies (percentages); continuous variables are presented as the mean (standard deviation) in normally distributed data or median (interquartile range (IQR)) in variables without a normal distribution (Shapiro-Wilk test). Categorical variables were analyzed using the chi-square or Fisher's exact tests. Continuous variables were analyzed using Student's $t$-test or the Mann-Whitney test when normality was not verified. Comparisons between multiple groups were performed using an analysis of variance (ANOVA) in normally distributed data and the Kruskal-Wallis test in variables without a normal distribution; the Bonferroni post-hoc correction was used for multiple pairwise comparisons. Pearson's correlation was used to test correlations between continuous variables. Three distinct multivariable logistic regression models were successively tested: (1) using classical cardiovascular risk factors as the independent variables and PAD as the dependent variable; (2) using metabolic and inflammatory data and miRNA expression levels as the independent variables and active smoking as the dependent variable; and (3) using miRNAs and other laboratory parameters dysregulated in cigarette smokers as the independent variables and PAD as the dependent variable. Variables with a $p$-value of $<0.10$ in univariate analyses were tested in the multivariable models. A correction for collinearity was performed as appropriate. The level of significance was 
set at $\alpha=0.05$. Analyses were conducted using SPSS software, version 26.0 (IBM Corp, Armonk, NY, USA).

\section{Results}

3.1. Characteristics of Participants According to the Presence of PAD and Cigarette-Smoking Status

A total of 94 participants were recruited, including 58 without and 36 with PAD (Table 1). Patients with PAD presented a higher prevalence of classical cardiovascular risk factors (including cigarette smoking), concomitant coronary and carotid artery disease, and use of antiplatelet and statin therapy, as well as higher creatinine levels, compared to patients without PAD. The $\Delta \mathrm{Ct} \mathrm{miR}-27 \mathrm{~b}$ and $\Delta \mathrm{Ct}$ miR-146 values were significantly higher in patients with PAD (Table 1), corresponding to a 17.0- and 3.4-fold downregulation of miR-27b and miR-146 [38], respectively, in patients with PAD.

Of the 94 participants, 51 were never smokers, 28 were prior smokers, and 15 were active smokers (Table 2). The mean pack-year was 53 (22) in prior smokers and 45 (21) in active smokers, with a median time from cigarette-smoking cessation of 10 (7-11) years in prior smokers. The prevalence of PAD and the proportion of bilateral PAD (among patients with PAD) increased from never smokers to prior smokers and to active smokers. Moreover, the leukocyte, neutrophil, and lymphocyte counts were higher in active smokers compared with other groups. MiR-27b was the only dysregulated miRNA according to cigarette-smoking status; the $\Delta \mathrm{Ct}$ miR-27b values were significantly higher in active smokers compared with prior smokers $(p=0.004$; corresponding to a downregulation of miR-27b in active smokers), and there was a trend for higher $\Delta \mathrm{Ct}$ miR-27b values in active smokers compared with never smokers $(p=0.053$; corresponding to a trend for downregulation of miR-27b in active smokers), with no significant differences between never smokers and prior smokers.

Active smokers presented significantly higher $\Delta \mathrm{Ct}$ miR-27b values $(22.00(4.35)) \mathrm{com}$ pared with non-active smokers, including never smokers and prior smokers (18.66 (4.33)), corresponding to a 10.0-fold downregulation of miR-27b expression levels in active smokers [38] (Figure 1).

\subsection{Cigarette Smoking Was Independently Associated with the Presence of PAD}

Considering all the risk factors for the development of cardiovascular disease that differed according to the presence of PAD in the univariate analysis, the age, cigarettesmoking status, and creatinine levels were independently associated with the presence of PAD in the multivariate logistic regression analysis (Table 3).

\subsection{MiR-27b Was Dysregulated in Active Smokers Independently of Other Metabolic and Inflammatory Parameters}

Considering the metabolic and inflammatory parameters and the miRNAs dysregulated in active smokers in the univariate analysis, the leukocyte count and $\Delta \mathrm{Ct} \mathrm{miR}-27 \mathrm{~b}$ were independently associated with active smoking in the multivariate logistic regression analysis (Table 4).

\subsection{MiR-27b Was Independently Associated with the Presence of PAD}

Considering all the metabolic and inflammatory parameters and the miRNA (miR$27 \mathrm{~b})$ dysregulated in active smokers in the univariate analysis, only $\Delta \mathrm{Ct}$ miR-27b was independently associated with the presence of PAD $(\beta=1.13,95 \%$ confidence interval: $1.01-1.28, p=0.037)$. Moreover, $\Delta \mathrm{Ct}$ miR-27b was significantly higher in bilateral PAD (24.0 (17.2-25.7)) compared with unilateral PAD (20.3 (15.1-23.2), $p=0.041$ vs. bilateral PAD) and with absent PAD (18.3 (14.8-21.6), $p=0.004$ vs. bilateral PAD). Such results corresponded to a 4.0- and 52.0-fold reduction in miR-27b in bilateral PAD compared with unilateral and absent PAD, respectively [38]. 
Table 1. Characteristics of participants without and with peripheral artery disease.

\begin{tabular}{|c|c|c|c|}
\hline Characteristics of Participants & Without Peripheral Artery Disease & With Peripheral Artery Disease & $p$-Value \\
\hline$n$ & 58 & 36 & \\
\hline \multicolumn{4}{|l|}{ Clinical characteristics } \\
\hline Age, years & $61(53-70)$ & $68(60-73)$ & 0.009 \\
\hline Male, $n(\%)$ & $51(88)$ & $33(92)$ & 0.419 \\
\hline Hypertension, $n(\%)$ & $42(72)$ & $36(100)$ & $<0.001$ \\
\hline Dyslipidemia, $n(\%)$ & $48(83)$ & $35(97)$ & 0.031 \\
\hline Diabetes mellitus, $n(\%)$ & $15(26)$ & $17(47)$ & 0.029 \\
\hline Cigarette-smoking status, $n(\%)$ & & & 0.001 \\
\hline Never smoker & $39(67)$ & $12(33)$ & \\
\hline Prior smoker & $15(26)$ & $13(36)$ & \\
\hline Active smoker & $4(7)$ & $11(31)$ & \\
\hline LVEF > 50\%, $n(\%)$ & $58(100)$ & $36(100)$ & - \\
\hline Antiplatelet therapy, $n(\%)$ & $37(64)$ & $35(97)$ & $<0.001$ \\
\hline Statin therapy, $n(\%)$ & $42(72)$ & $32(91)$ & 0.023 \\
\hline Coronary artery disease, $n(\%)$ & $32(55)$ & $36(100)$ & $<0.001$ \\
\hline Carotid artery disease, $n(\%)$ & $12(55)$ & $18(50)$ & 0.003 \\
\hline \multicolumn{4}{|l|}{ Peripheral artery disease } \\
\hline Bilateral disease, $n(\%)$ & $0(0)$ & $25(69)$ & $<0.001$ \\
\hline Prior bypass surgery, $n(\%)$ & $0(0)$ & $8(22)$ & $<0.001$ \\
\hline \multicolumn{4}{|l|}{ Laboratory parameters } \\
\hline Hemoglobin, $\mathrm{g} / \mathrm{dL}$ & $13.8(1.5)$ & $13.6(1.6)$ & 0.586 \\
\hline Leukocyte count, $10^{9} / \mathrm{L}$ & $7.0(1.9)$ & $7.7(1.7)$ & 0.081 \\
\hline Neutrophil count, $10^{9} / \mathrm{L}$ & $4.0(1.7)$ & $4.5(1.4)$ & 0.192 \\
\hline Lymphocyte count, $10^{9} / \mathrm{L}$ & $1.9(1.6-2.3)$ & $2.2(1.6-2.7)$ & 0.100 \\
\hline Neutrophil/lymphocyte ratio & $2.2(1.0)$ & $2.2(1.0)$ & 0.943 \\
\hline Platelet count, $10^{9} / \mathrm{L}$ & $223(58)$ & $227(44)$ & 0.749 \\
\hline Fasting glycemia, mg/dL & $92(83-104)$ & $90(82-121)$ & 0.978 \\
\hline Percentage of glycosylated hemoglobin & $5.7(5.4-6.2)$ & $5.9(5.5-7.4)$ & 0.295 \\
\hline Creatinine, $\mathrm{mg} / \mathrm{dL}$ & $0.85(0.77-0.97)$ & $0.94(0.80-1.34)$ & 0.036 \\
\hline Total cholesterol, mg/dL & $164(130-206)$ & $166(147-205)$ & 0.781 \\
\hline LDL-cholesterol, mg/dL & $92(72-130)$ & $109(83-135)$ & 0.250 \\
\hline HDL-cholesterol, mg/dL & $43(34-51)$ & $36(31-43)$ & 0.062 \\
\hline Triglycerides, mg/dL & $115(71-163)$ & $117(88-178)$ & 0.429 \\
\hline C-reactive protein, $\mathrm{mg} / \mathrm{L}$ & $4.0(1.9)$ & $3.6(1.5)$ & 0.529 \\
\hline \multicolumn{4}{|l|}{$\operatorname{miRNAs}^{1}$} \\
\hline miR-21 & $14.89(4.51)$ & $15.99(4.65)$ & 0.282 \\
\hline $\operatorname{miR}-27 \mathrm{~b}$ & $18.23(14.58-21.59)$ & $22.32(16.50-24.13)$ & 0.032 \\
\hline $\operatorname{miR}-29 a$ & $20.42(3.57)$ & $21.80(3.12)$ & 0.152 \\
\hline miR-126 & $16.89(14.89-22.46)$ & $19.69(16.28-24.06)$ & 0.060 \\
\hline miR-146 & $18.70(3.40)$ & $20.48(4.23)$ & 0.048 \\
\hline $\operatorname{miR}-218$ & $22.69(22.48-23.33)$ & $14.49(-8.6-23.50)$ & 0.186 \\
\hline
\end{tabular}

Categorical variables are expressed as the frequency (percentage), and continuous variables are expressed as the mean (standard deviation) or median (interquartile range). HDL-high-density lipoprotein; LDL-low-density lipoprotein; LVEF-left-ventricular ejection fraction; miRNA—-microRNA. ${ }^{1}$ Delta cycle threshold $(\Delta \mathrm{Ct})$ values are presented for each miRNA (higher $\Delta \mathrm{Ct}$ values correspond to lower miRNA expression levels). 
Table 2. Characteristics of participants according to cigarette-smoking status.

\begin{tabular}{|c|c|c|c|c|}
\hline Characteristics of Participants & Never Smokers & Prior Smokers & Active Smokers & $p$-Value \\
\hline$n$ & 51 & 28 & 15 & \\
\hline \multicolumn{5}{|l|}{ Clinical characteristics } \\
\hline Age, years & $65(56-73)$ & $67(58-71)$ & $59(53-68)$ & 0.415 \\
\hline Male, $n(\%)$ & $43(84)$ & $28(100)$ & $13(87)$ & 0.090 \\
\hline Hypertension, $n(\%)$ & $36(71)$ & $28(100)$ & $14(93)$ & 0.002 \\
\hline Dyslipidemia, $n(\%)$ & $43(84)$ & $26(93)$ & $14(93)$ & 0.424 \\
\hline Diabetes mellitus, $n(\%)$ & $17(33)$ & $10(36)$ & $5(33)$ & 0.975 \\
\hline LVEF $>50 \%, n(\%)$ & $51(100)$ & $28(100)$ & $15(100)$ & - \\
\hline Antiplatelet therapy, $n(\%)$ & $36(71)$ & $24(86)$ & $12(80)$ & 0.298 \\
\hline Statin therapy, $n(\%)$ & $37(73)$ & $24(86)$ & $13(93)$ & 0.156 \\
\hline Coronary artery disease, $n(\%)$ & $31(61)$ & $24(86)$ & $13(86)$ & 0.024 \\
\hline Carotid artery disease, $n(\%)$ & $14(51)$ & $10(36)$ & $6(40)$ & 0.576 \\
\hline \multicolumn{5}{|l|}{ Peripheral artery disease } \\
\hline Number of patients & $12(24)$ & $13(46)$ & $11(73)$ & 0.001 \\
\hline Bilateral disease, $n(\%)$ & $8(16)$ & $11(39)$ & $6(40)$ & 0.002 \\
\hline Prior bypass surgery, $n(\%)$ & $2(4)$ & $5(18)$ & $1(7)$ & 0.101 \\
\hline \multicolumn{5}{|l|}{ Laboratory parameters } \\
\hline Hemoglobin, g/dL & $13.4(1.5)$ & $14.1(1.4)$ & $14.1(1.4)$ & 0.063 \\
\hline Leukocyte count, $10^{9} / \mathrm{L}$ & $6.6(1.5)$ & $7.3(1.8)$ & $9.2(1.8)$ & $<0.001^{1,2}$ \\
\hline Neutrophil count, $10^{9} / \mathrm{L}$ & $3.8(3.0-4.4)$ & $3.9(3.2-5.3)$ & $4.6(3.7-5.8)$ & $<0.001^{1,2}$ \\
\hline Lymphocyte count, $10^{9} / \mathrm{L}$ & $1.8(1.5-2.2)$ & $2.1(1.6-2.4)$ & $2.3(1.8-3.5)$ & $0.027^{1}$ \\
\hline Neutrophil/lymphocyte ratio & $2.0(1.5-3.0)$ & $2.2(1.7-2.7)$ & $2.3(1.9-2.8)$ & 0.568 \\
\hline Platelet count, $10^{9} / \mathrm{L}$ & $219(51)$ & $218(54)$ & $255(51)$ & 0.058 \\
\hline Fasting glycemia, mg/dL & $92(83-116)$ & $91(85-112)$ & $89(72-117)$ & 0.565 \\
\hline $\begin{array}{c}\text { Percentage of glycosylated } \\
\text { hemoglobin }\end{array}$ & $5.7(5.3-7.1)$ & $5.8(5.4-6.2)$ & $5.9(5.6-6.1)$ & 0.787 \\
\hline Creatinine, $\mathrm{mg} / \mathrm{dL}$ & $0.86(0.78-1.08)$ & $0.86(0.76-1.00)$ & $1.01(0.75-1.71)$ & 0.447 \\
\hline Total cholesterol, mg/dL & $178(51)$ & $154(43)$ & $172(48)$ & 0.060 \\
\hline LDL-cholesterol, mg/dL & $108(41)$ & $89(38)$ & $116(32)$ & 0.059 \\
\hline HDL-cholesterol, mg/dL & $42(34-51)$ & $41(29-46)$ & $35(31-42)$ & 0.236 \\
\hline Triglycerides, mg/dL & $116(79-156)$ & $104(73-178)$ & $158(112-243)$ & 0.139 \\
\hline C-reactive protein, $\mathrm{mg} / \mathrm{L}$ & $3.5(1.6)$ & $3.7(1.8)$ & $4.0(1.9)$ & 0.339 \\
\hline \multicolumn{5}{|l|}{ miRNAs $^{3}$} \\
\hline miR-21 & $15.44(4.40)$ & $14.55(4.62)$ & $16.42(5.09)$ & 0.454 \\
\hline $\operatorname{miR}-27 b$ & $19.29(4.42)$ & $17.44(3.98)$ & $22.00(4.35)$ & $0.014^{2}$ \\
\hline $\operatorname{miR}-29 a$ & $21.01(3.04)$ & $19.74(3.86)$ & $23.19(3.12)$ & 0.059 \\
\hline miR-126 & $17.42(15.20-23.98)$ & $16.10(14.89-19.48)$ & $22.40(17.65-24.15)$ & 0.075 \\
\hline $\operatorname{miR}-146$ & $20.03(15.74-22.21)$ & $17.79(16.26-20.12)$ & $21.69(18.23-23.58)$ & 0.150 \\
\hline miR-218 & $22.31(15.67-23.02)$ & $22.31(15.67-23.02)$ & $8.45(-8.46-21.50)$ & 0.120 \\
\hline
\end{tabular}

Categorical variables are expressed as the frequency (percentage), and continuous variables are expressed as the mean (standard deviation) or median (interquartile range). HDL-high-density lipoprotein; LDL-low-density lipoprotein; LVEF-left-ventricular ejection fraction; miRNA-microRNA. ${ }^{1} p<0.05$, active smokers vs. never smokers; ${ }^{2} p<0.05$, active smokers vs. prior smokers; ${ }^{3}$ delta cycle threshold $(\Delta \mathrm{Ct})$ values are presented for each miRNA (higher $\Delta \mathrm{Ct}$ values correspond to lower expression levels of candidate miRNAs). 


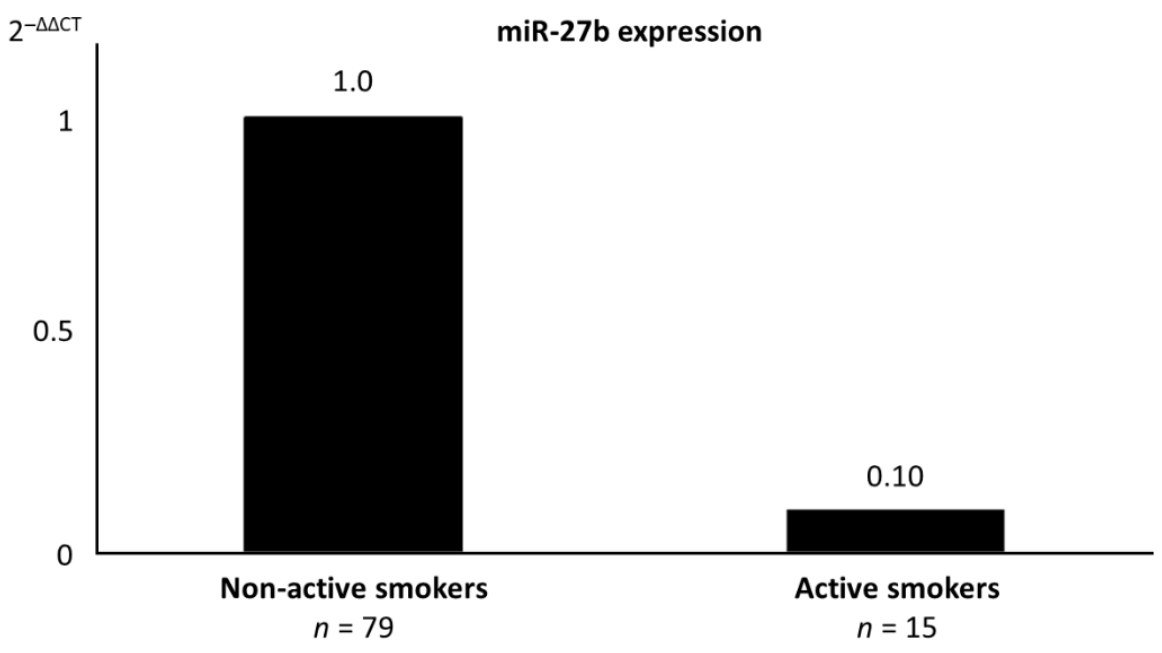

Figure 1. Relative expression of miR-27b according to the cigarette-smoking status. The relative expression of miR-27b ( $\left.2^{-\Delta \Delta \mathrm{Ct}}\right)$ is presented for non-active smokers, including never smokers and prior smokers, and for active smokers.

Table 3. Predictors of peripheral artery disease in multivariate logistic regression analysis.

\begin{tabular}{cccc}
\hline Independent Predictors & $\boldsymbol{\beta}$ & $\mathbf{9 5 \%} \mathbf{C I}$ & $\boldsymbol{p}$-Value \\
\hline Age, years & 1.11 & $1.04-1.18$ & 0.002 \\
Cigarette smoking & 4.11 & $1.89-8.95$ & 0.031 \\
Creatinine, mg/dL & 6.29 & $1.12-33.49$ & $<0.001$ \\
\hline
\end{tabular}

95\% CI-95\% confidence interval.

Table 4. Parameters dysregulated in active smokers in multivariate logistic regression analysis.

\begin{tabular}{cccc}
\hline Independent Predictors & $\boldsymbol{\beta}$ & $\mathbf{9 5 \%} \mathbf{C I}$ & $\boldsymbol{p}$-Value \\
\hline Leukocyte count & 2.33 & $1.37-3.94$ & 0.002 \\
$\Delta$ Ct miR-27b & 1.33 & $1.02-1.72$ & 0.034 \\
\hline
\end{tabular}

95\% CI-95\% confidence interval, $\Delta \mathrm{Ct}$-delta cycle threshold.

\section{Discussion}

In this prospective study, three main findings stood out: cigarette smoking was associated with the presence of PAD, cigarette smoking was associated with miR-27b downregulation, and miR-27b downregulation was associated with the presence and severity of PAD. These results suggest that miR- $27 \mathrm{~b}$ mediates the proatherogenic effects of cigarette smoking.

Cigarette smoking is a recognized causal risk factor for PAD development [1,2]. On the other hand, the expression of circulating miRNAs is influenced by exogenous factors, such as cigarette smoking [4]. In this study, the atheroprotective miR-27b was downregulated in active smokers compared with non-active smokers (including never smokers and prior smokers), independently of other metabolic and inflammatory parameters. These results suggest a detrimental effect of active cigarette smoking on miR-27b expression, similar to the reported effect of cigarette smoking on other atheroprotective miRNAs [39]. MiR$27 \mathrm{~b}$ was significantly downregulated in active smokers compared with prior smokers but not with never smokers, although there was a trend towards miR-27b downregulation in active smokers compared with never smokers. The latter may be explained by the limited sample size used in this study. Based on an extensive post-hoc analysis, the absence of differences in miR-27b expression levels between active smokers and never smokers is difficult to explain, and we did not find additional factors that could contribute to such results. Nevertheless, the numerical differences between active smokers and never smokers were close to the margin of statistical significance and are consistent with a culprit effect 
of active smoking in downregulating miR-27b compared with prior smokers and, likely, never smokers as well. There were no significant differences in miR-27b expression levels between prior smokers and never smokers. Such results may be explained by a sensitivity of miR-27b expression levels to active smoking without a legacy effect [39,40]. Specifically, smoking cessation was reported to completely revert the dysregulation of some miRNAs observed in active smokers [39,40], and this may also be the case of miR-27b. These data reinforce the atheroprotective effects of smoking cessation. Published data addressing the effect of smoking on miR-27a/b expression are limited [39-41]. Of two studies addressing miR-27a, one reported an upregulation and the other reported no dysregulation in active smokers $[39,40]$. Nevertheless, miR-27a and miR-27b may differ in their mechanisms of action and expression levels in specific diseases, and the aforementioned results concerning $\mathrm{miR}-27 \mathrm{a}$ expression in active smokers may not be applicable to miR-27b [42-44]. Specifically, for miR-27b, a nonsignificant downregulation was reported in human oral keratinocytes in association with cigarette smoke exposure [41]. In our study, the downregulation of circulating miR-27b in active smokers was significant after adjusting for other metabolic and inflammatory parameters.

The dysregulation of some circulating miRNAs is known to be associated with the development of atherosclerosis, and $\mathrm{miR}-27 \mathrm{~b}$ was reported to be atheroprotective on the basis of experimental studies [19-26]. This possibly explains the association between the reduced miR-27b expression and the higher prevalence and severity of PAD observed in this study. Complementary atheroprotective mechanisms of miR-27b were previously reported [19-26]. Xie W. et al. [19] elegantly showed that miR-27 reduces vascular lipid accumulation, partially mediated by the suppression of expression of scavenger receptors associated with lipid uptake in vascular macrophages. Interestingly, systemic treatment with miR-27 decreased aortic plaque size and lipid content in mice [19]. Consistently, in another study, miR-27b was identified as a crucial regulatory hub in lipid metabolism in human and mouse liver and was shown to downregulate the expression of key genes involved in lipid metabolism, including Angptl3 and Gpam, which mitigates the accumulation of lipids in circulation [20]. Regarding inflammation, miR-27b downregulates lipoprotein lipase gene expression and thereby reduces vascular inflammatory response, which limits atherogenesis [19]. Moreover, miR-27b restrains the activity of NF- $\mathrm{kB}$ and the production of several pro-inflammatory factors, including interleukin (IL)-1 $\beta$, IL-6, and tumor necrosis factor alpha [21], inhibits interleukin-17-induced monocyte chemoattractant protein-1 [22] and targets Bcl-2-associated athanogene 2 in macrophages [21]. This contributes to a decreased monocyte-macrophage activation [23]. Considering the key role of vascular inflammation, particularly the monocyte-macrophage activation, in the development and expression of atherosclerosis, the aforementioned molecular mechanisms are consistent with the atheroprotective effects of miR-27b [45,46]. On the other hand, as miR-27b represses repulsive semaphorins, especially semaphorin $6 \mathrm{~A}$, it facilitates the formation of tight endothelial monolayers and stable vessels in response to shear stress [24]. In addition, miR-27b was identified as a proangiogenic miRNA [25], regulating angiogenesis through the angiogenic inhibitor semaphorin 6A and Notch ligand Dll4 [23,26]. Regarding studies addressing miR-27b expression in patients with PAD, data is conflicting. Signorelli et al. [11] reported an upregulation of miR-27b in patients with PAD compared with controls. On the other hand, Stather et al. [10] reported a downregulation of miR$27 \mathrm{~b}$ in patients with PAD, and our findings are consistent with their results. Contrary to the study by Signorelli et al. [11], Stather et al. [10] confirmed the presence of PAD using imaging methods, used one derivation and two validation sample sets, reported the diagnostic accuracy of miR-27b for detecting PAD, and presented a pathway enrichment analysis. There is a known biological variation in miRNAs measurements, occasionally with conflicting expression levels among different studies focused on the same disease [47]. The miR-27b downregulation observed in our study reinforces the results of the study by Stather et al. [10], where a very robust methodology was used. 
The downregulation of miR-27b in active smokers and the independent association between miR-27b and the presence of PAD in this study suggest that miR-27b is downregulated due to active cigarette smoking and that such dysregulation contributes to PAD (Figure 2). The results are, therefore, consistent with miR-27b acting as a mediator of cigarette-smoking toxicity, specifically in PAD development.

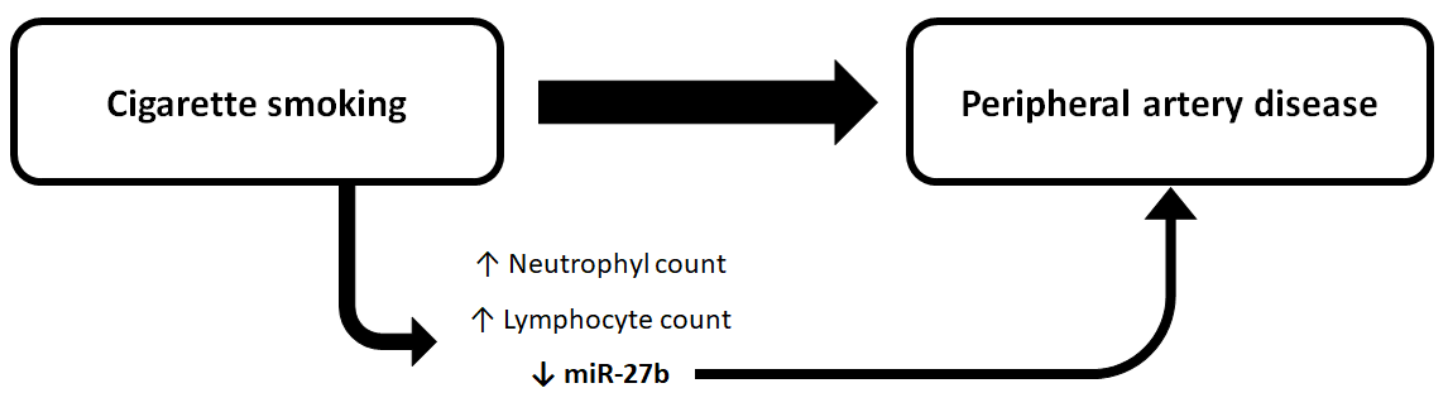

Figure 2. Putative role of miR-27b in the toxicity induced by cigarette smoking. Cigarette smoking was associated with the presence of peripheral artery disease and with miR-27b downregulation; downregulation of the atheroprotective miR-27b was associated with the presence and severity of peripheral artery disease; miR-27b may mediate the atherogenesis induced by cigarette smoking. The suspension points represent metabolic and inflammatory parameters potentially dysregulated in association with cigarette smoking, in addition to neutrophil count, lymphocyte count, and miR-27b expression.

In this study, miR-146 was also downregulated in patients with PAD. MiR-146 is induced in endothelial cells in response to pro-inflammatory cytokines and acts as a negative feedback regulator of inflammatory signaling in endothelial cells by dampening the activation of pro-inflammatory transcriptional programs, including the NF- $\mathrm{kB}, \mathrm{AP}-1$, and MAPK/EGR pathways, and by promoting eNOS expression $[3,7,48]$. Moreover, miR146 a was reported to decrease endothelial inflammation by inhibiting NAPDH Oxidase 4 expression in a diabetic atherothrombosis model [49]. The anti-inflammatory effects of miR-146 contribute to counteracting atherogenesis $[3,7,48,49]$ and may explain the association between miR-146 downregulation and the presence of PAD observed in our study. The remaining miRNAs (miR-21, miR-29a, miR-126, and miR-218) were not dysregulated in association with PAD, despite their involvement in biological pathways associated with atherosclerosis regulation, as reported in experimental studies [48,50-60]. A comprehensive review of their biological roles is out of the scope of this study, but some of the main targets are herein addressed. MiR-21 has both atheroprotective and proatherogenic effects [50]. It enhances vascular smooth muscle cell migration and proliferation by targeting TSP- 1 and c-Sk [50,51]. On the other hand, miR-21 inhibits both endothelial cell apoptosis, through PTEN [52], and endothelial cell proliferation, through RhoB [53]. In addition, miR-21 promotes inflammatory activation of endothelial cells by targeting PPAR $\alpha$, which induces the expression of adhesion molecules and cytokines [54]. MiR-29a acts in distinct pathways, as it represses transcripts of several components of the extracellular matrix; of note, miR-29a downregulates the expression of ELN, COL1A1, and COL3A1, resulting in a reduction of the elastin and collagen content in the atherosclerotic plaque [55,56]. In fact, antagonizing the antifibrotic effect of miR-29a leads to a reduced size of atherosclerotic lesions, enhanced fibrous cap thickness, and reduced necrotic zones [55]. MiR-126 promotes endothelial proliferation and limits atherosclerosis by suppressing Dlk1 [57]. Interestingly, miR-126 is a mechanosensitive miRNA that is downregulated through the transcription factor klf2a in response to disturbed flow and shear stress [58]. Finally, miR-218 regulates Slit/Robo signaling through the repression of Robo1, Robo2, and glucuronyl C5-epimerase and thereby regulates endothelial cell migration and vascular patterning $[59,60]$. As supported by the aforementioned experimental data, further clinical studies are warranted to confirm the role of these miRNAs as biomarkers of atherosclerosis. 
There are strengths of this study that should be acknowledged. As far as we know, we describe for the first time coexistent associations among cigarette-smoking status, dysregulation of circulating miR-27b, and PAD. The results were consistent with the aforementioned biological roles of miR-27b in experimental studies [19-26]. Moreover, the miR-27b downregulation in more severe, bilateral PAD further added to the consistency of the results. Importantly, the multivariable analyses carried out in this study, adjusting for confounders, contributed to the accuracy of our findings.

Our study has some limitations. The results indicate associations among cigarette smoking, miR-27b dysregulation, and PAD development, but not a causal effect. Nevertheless, the adjustment for confounders in the multivariable analyses and the consistency of the results with the aforementioned experimental data [19-26] suggest that miR-27b is very likely a mediator in such a pathophysiology chain. Of note, this is a single-center study that included only European participants, which may limit the applicability of results to other clinical settings. Populations with different ethnicities may express distinct microRNA profiles, either in healthy individuals or in specific disease subsets [61,62]. Therefore, further multicentric studies recruiting participants from distinct geographical areas are warranted for external validation of our findings.

\section{Conclusions}

Cigarette smoking was associated with the presence of PAD. Active smokers, but not prior smokers, presented a downregulation of miR-27b, and such dysregulation was associated with the presence and severity of PAD. These unreported data suggest that miR-27b mediates the proatherogenic effects of cigarette smoking and that cigarette smoking cessation may be associated with an attenuation of miR-27b dysregulation. Our results provide insights into the pathophysiology of cigarette-smoking toxicity and associated PAD.

Author Contributions: Conceptualization, T.P.-d.-S., P.N. and M.M.C.; methodology, P.N., M.C.C. and A.F.G.; validation, P.N., M.C.C., A.F.G. and F.J.E.; formal analysis, T.P.-d.-S. and P.N.; investigation, T.P.-d.-S., P.N., M.C.C., A.F.G., M.S. and F.S.; resources, M.S. and F.S.; data curation, T.P.-d.-S., M.S. and F.S.; writing - original draft preparation, T.P.-d.-S. and P.N.; writing-review and editing, T.P.-d.-S., P.N., M.C.C., A.F.G., M.S., F.S., F.J.E., R.C.F. and M.M.C.; visualization, T.P.-d.-S.; supervision, P.N., R.C.F. and M.M.C.; project administration, P.N. and M.M.C. All authors have read and agreed to the published version of the manuscript.

Funding: This research received no external funding.

Institutional Review Board Statement: The study was conducted according to the guidelines of the Declaration of Helsinki, and approved by the ethics committees of the involved institutions (Centro Hospitalar Universitário de Lisboa Central, Nr. 245/2015, on 1 October 2015, and NOVA Medical School | Faculdade de Ciências Médicas, Universidade NOVA de Lisboa, Nr. 000176, on 11 November 2015).

Informed Consent Statement: Informed consent was obtained from all subjects involved in the study.

Data Availability Statement: The data presented in this study are available on request from the corresponding author. The data are not publicly available due to personal data protection.

Acknowledgments: This study is part of the PhD thesis program of one of the authors (T.P.-d.-S.), supervised (M.M.C.) and co-supervised (P.N.) by the other two, conducted at the NOVA Medical School | Faculdade de Ciências Médicas, Universidade NOVA de Lisboa, Lisbon, Portugal. The authors are grateful to Joana Castro, from Medinres-Medical Information and Research, for her advice with respect to the statistical analysis.

Conflicts of Interest: The authors declare no conflict of interest. 


\section{References}

1. Siasos, G.; Tsigkou, V.; Kokkou, E.; Oikonomou, E.; Vavuranakis, M.; Vlachopoulos, C.; Verveniotis, A.; Limperi, M.; Genimata, V.; Papavassiliou, A.G.; et al. Smoking and Atherosclerosis: Mechanisms of Disease and New Therapeutic Approaches. Curr. Med. Chem. 2014, 21, 3936-3948. [CrossRef]

2. Lu, J.T.; Creager, M.A. The relationship of cigarette smoking to peripheral arterial disease. Rev. Cardiovasc. Med. 2004, 5, 189-193.

3. Feinberg, M.W.; Moore, K.J. MicroRNA Regulation of Atherosclerosis. Circ. Res. 2016, 118, 703-720. [CrossRef] [PubMed]

4. Willinger, C.M.; Rong, J.; Tanriverdi, K.; Courchesne, P.L.; Huan, T.; Wasserman, G.A.; Lin, H.; Dupuis, J.; Joehanes, R.; Jones, M.R.; et al. MicroRNA Signature of Cigarette Smoking and Evidence for a Putative Causal Role of MicroRNAs in SmokingRelated Inflammation and Target Organ Damage. Circ. Cardiovasc. Genet. 2017, 10. [CrossRef]

5. Kaur, G.; Begum, R.; Thota, S.; Batra, S. A systematic review of smoking-related epigenetic alterations. Arch. Toxicol. 2019, 93, 2715-2740. [CrossRef]

6. Pereira-da-Silva, T.; Coutinho Cruz, M.; Carrusca, C.; Cruz Ferreira, R.; Napoleão, P.; Mota Carmo, M. Circulating mi-croRNA profiles in different arterial territories of stable atherosclerotic disease: A systematic review. Am. J. Cardiovasc. Dis. 2018, 8, 1-13.

7. Andreou, I.; Sun, X.; Stone, P.H.; Edelman, E.R.; Feinberg, M.W. miRNAs in atherosclerotic plaque initiation, progression, and rupture. Trends Mol. Med. 2015, 21, 307-318. [CrossRef]

8. Chen, L.-J.; Lim, S.H.; Yeh, Y.-T.; Lien, S.-C.; Chiu, J.-J. Roles of microRNAs in atherosclerosis and restenosis. J. Biomed. Sci. 2012, 19, 79. [CrossRef]

9. Navickas, R.; Gal, D.; Laucevičius, A.; Taparauskaitè, A.; Zdanytè, M.; Holvoet, P. Identifying circulating microRNAs as biomarkers of cardiovascular disease: A systematic review. Cardiovasc. Res. 2016, 111, 322-337. [CrossRef]

10. Stather, P.W.; Sylvius, N.; Wild, J.B.; Choke, E.; Sayers, R.D.; Bown, M.J. Differential MicroRNA Expression Profiles in Peripheral Arterial Disease. Circ. Cardiovasc. Genet. 2013, 6, 490-497. [CrossRef]

11. Signorelli, S.S.; Volsi, G.L.; Pitruzzella, A.; Fiore, V.; Mangiafico, M.; Vanella, L.; Parenti, R.; Rizzo, M.; Volti, G.L. Circulating miR-130a, miR-27b, and miR-210 in Patients With Peripheral Artery Disease and Their Potential Relationship With Oxidative Stress. Angiology 2016, 67, 945-950. [CrossRef]

12. Wang, J.; Song, Y.; Zhang, Y.; Xiao, H.; Sun, Q.; Hou, N.; Guo, S.; Wang, Y.; Fan, K.; Zhan, D.; et al. Cardiomyocyte overexpression of miR-27b induces cardiac hypertrophy and dysfunction in mice. Cell Res. 2011, 22, 516-527. [CrossRef]

13. Liu, B.; Chen, W.; Cao, G.; Dong, Z.; Xu, J.; Luo, T.; Zhang, S. MicroRNA-27b inhibits cell proliferation in oral squamous cell carcinoma by targeting FZD7 and Wnt signaling pathway. Arch. Oral Biol. 2017, 83, 92-96. [CrossRef]

14. Murata, Y.; Yamashiro, T.; Kessoku, T.; Jahan, I.; Usuda, H.; Tanaka, T.; Okamoto, T.; Nakajima, A.; Wada, K. Up-Regulated MicroRNA-27b Promotes Adipocyte Differentiation via Induction of Acyl-CoA Thioesterase 2 Expression. BioMed Res. Int. 2019, 2019, 1-9. [CrossRef]

15. Cazalla, D.; Steitz, J.A. Down-Regulation of a Host microRNA by a Viral Noncoding RNA. Cold Spring Harb. Symp. Quant. Biol. 2010, 75, 321-324. [CrossRef] [PubMed]

16. Guo, Y.E.; Riley, K.J.; Iwasaki, A.; Steitz, J.A. Alternative Capture of Noncoding RNAs or Protein-Coding Genes by Herpesviruses to Alter Host T Cell Function. Mol. Cell 2014, 54, 67-79. [CrossRef]

17. Marcinowski, L.; Tanguy, M.; Krmpotic, A.; Rädle, B.; Lisnić, V.J.; Tuddenham, L.; Chane-Woon-Ming, B.; Ruzsics, Z.; Erhard, F.; Benkartek, C.; et al. Degradation of Cellular miR-27 by a Novel, Highly Abundant Viral Transcript Is Important for Efficient Virus Replication In Vivo. PLoS Pathog. 2012, 8, e1002510. [CrossRef]

18. Machitani, M.; Sakurai, F.; Wakabayashi, K.; Nakatani, K.; Tachibana, M.; Mizuguchi, H. MicroRNA miR-27 Inhibits Adenovirus Infection by Suppressing the Expression of SNAP25 and TXN2. J. Virol. 2017, 91, e00159-e00217. [CrossRef]

19. Xie, W.; Li, L.; Zhang, M.; Cheng, H.-P.; Gong, D.; Lv, Y.-C.; Yao, F.; He, P.-P.; Ouyang, X.-P.; Lan, G.; et al. MicroRNA-27 Prevents Atherosclerosis by Suppressing Lipoprotein Lipase-Induced Lipid Accumulation and Inflammatory Response in Apolipoprotein E Knockout Mice. PLoS ONE 2016, 11, e0157085. [CrossRef]

20. Vickers, K.C.; Shoucri, B.M.; Levin, M.G.; Wu, H.; Pearson, D.S.; Osei-Hwedieh, D.; Collins, F.S.; Remaley, A.T.; Sethupathy, P. MicroRNA-27b is a regulatory hub in lipid metabolism and is altered in dyslipidemia. Hepatology 2013, 57, 533-542. [CrossRef] [PubMed]

21. Liang, S.; Song, Z.; Wu, Y.; Gao, Y.; Gao, M.; Liu, F.; Wang, F.; Zhang, Y. MicroRNA-27b Modulates Inflammatory Response and Apoptosis during Mycobacterium tuberculosis Infection. J. Immunol. 2018, 200, 3506-3518. [CrossRef]

22. Huang, K.; Shen, Y.; Wei, X.; Zhang, F.; Liu, Y.; Ma, L. Inhibitory effect of microRNA-27b on interleukin 17 (IL-17)-induced monocyte chemoattractant protein-1 (MCP1) expression. Genet. Mol. Res. 2016, 15. [CrossRef]

23. Veliceasa, D.; Biyashev, D.; Qin, G.; Misener, S.; Mackie, A.R.; Kishore, R.; Volpert, O.V. Therapeutic manipulation of angiogenesis with miR-27b. Vasc. Cell 2015, 7, 6. [CrossRef]

24. Boon, R.A.; Hergenreider, E.; Dimmeler, S. Atheroprotective mechanisms of shear stress-regulated microRNAs. Thromb. Haemost. 2012, 108, 616-620. [CrossRef]

25. Kuehbacher, A.; Urbich, C.; Zeiher, A.M.; Dimmeler, S. Role of Dicer and Drosha for Endothelial MicroRNA Expression and Angiogenesis. Circ. Res. 2007, 101, 59-68. [CrossRef]

26. Urbich, C.; Kaluza, D.; Frömel, T.; Knau, A.; Bennewitz, K.; Boon, R.A.; Bonauer, A.; Doebele, C.; Boeckel, J.-N.; Hergenreider, E.; et al. MicroRNA-27a/b controls endothelial cell repulsion and angiogenesis by targeting semaphorin 6A. Blood 2012, 119, 1607-1616. [CrossRef] 
27. Hwang, J.Y. Doppler ultrasonography of the lower extremity arteries: Anatomy and scanning guidelines. Ultrasonography 2017, 36, 111-119. [CrossRef]

28. Aboyans, V.; Ricco, J.-B.; Bartelink, M.-L.E.; Björck, M.; Brodmann, M.; Cohnert, T.; Collet, J.-P.; Czerny, M.; De Carlo, M.; Debus, S.; et al. Editor's Choice-2017 ESC Guidelines on the Diagnosis and Treatment of Peripheral Arterial Diseases, in collaboration with the European Society for Vascular Surgery (ESVS). Eur. J. Vasc. Endovasc. Surg. 2018, 55, 305-368. [CrossRef]

29. Collins, R.; Burch, J.; Cranny, G.; Aguiar-Ibáñez, R.; Craig, D.; Wright, K.; Berry, E.; Gough, M.; Kleijnen, J.; Westwood, M. Duplex ultrasonography, magnetic resonance angiography, and computed tomography angiography for diagnosis and assessment of symptomatic, lower limb peripheral arterial disease: Systematic review. BMJ 2007, 334, 1257. [CrossRef]

30. Hackshaw, A.; Morris, J.K.; Boniface, S.; Tang, J.-L.; Milenković, D. Low cigarette consumption and risk of coronary heart disease and stroke: Meta-analysis of 141 cohort studies in 55 study reports. BMJ 2018, 360, 5855. [CrossRef] [PubMed]

31. Deo, A.; Carlsson, J.; Lindlöf, A. How to Choose A Normalization Strategy for Mirna Quantitative Real-Time (QPCR) Arrays. J. Bioinform. Comput. Biol. 2011, 9, 795-812. [CrossRef] [PubMed]

32. Wolfinger, R.D.; Beedanagari, S.; Boitier, E.; Chen, T.; Couttet, P.; Ellinger-Ziegelbauer, H.; Guillemain, G.; Mariet, C.; Mouritzen, P.; O'Lone, R.; et al. Two approaches for estimating the lower limit of quantitation (LLOQ) of microRNA levels assayed as exploratory biomarkers by RT-qPCR. BMC Biotechnol. 2018, 18, 6. [CrossRef]

33. Zhang, X.; Shao, S.; Geng, H.; Yu, Y.; Wang, C.; Liu, Z.; Yu, C.; Jiang, X.; Deng, Y.; Gao, L.; et al. Expression Profiles of Six Circulating MicroRNAs Critical to Atherosclerosis in Patients With Subclinical Hypothyroidism: A Clinical Study. J. Clin. Endocrinol. Metab. 2014, 99, 766-774. [CrossRef] [PubMed]

34. Kumar, D.; Narang, R.; Sreenivas, V.; Rastogi, V.; Bhatia, J.; Saluja, D.; Srivastava, K. Circulatory miR-133b and miR-21 as Novel Biomarkers in Early Prediction and Diagnosis of Coronary Artery Disease. Genes 2020, 11, 164. [CrossRef]

35. Vegter, E.L.; Ovchinnikova, E.S.; Van Veldhuisen, D.J.; Jaarsma, T.; Berezikov, E.; Van Der Meer, P.; Voors, A.A. Low circulating microRNA levels in heart failure patients are associated with atherosclerotic disease and cardiovascular-related rehospitalizations. Clin. Res. Cardiol. 2017, 106, 598-609. [CrossRef]

36. Stather, P.W.; Sylvius, N.; Sidloff, D.A.; Dattani, N.; Verissimo, A.; Wild, J.B.; Butt, H.Z.; Choke, E.; Sayers, R.D.; Bown, M.J. Identification of microRNAs associated with abdominal aortic aneurysms and peripheral arterial disease. BJS 2015, 102, 755-766. [CrossRef]

37. Huang, Y.-Q.; Ying-Ling, Z.; Chen, J.-Y.; Zhou, Y.-L.; Cai, A.-P.; Huang, C.; Feng, Y.-Q. The Association of Circulating MiR-29b and Interleukin-6 with Subclinical Atherosclerosis. Cell. Physiol. Biochem. 2017, 44, 1537-1544. [CrossRef]

38. Livak, K.J.; Schmittgen, T.D. Analysis of relative gene expression data using real-time quantitative PCR and the $2^{-\Delta \Delta C T}$ Method. Methods 2001, 25, 402-408. [CrossRef]

39. Takahashi, K.; Yokota, S.-I.; Tatsumi, N.; Fukami, T.; Yokoi, T.; Nakajima, M. Cigarette smoking substantially alters plasma microRNA profiles in healthy subjects. Toxicol. Appl. Pharmacol. 2013, 272, 154-160. [CrossRef]

40. Suzuki, K.; Yamada, H.; Nagura, A.; Ohashi, K.; Ishikawa, H.; Yamazaki, M.; Ando, Y.; Ichino, N.; Osakabe, K.; Sugimoto, K.; et al. Association of cigarette smoking with serum microRNA expression among middle-aged Japanese adults. Fujita Med J. 2013, 2, 1-5. [CrossRef]

41. Bhat, M.Y.; Advani, J.; Rajagopalan, P.; Patel, K.; Nanjappa, V.; Solanki, H.S.; Patil, A.H.; Bhat, F.A.; Mathur, P.P.; Nair, B.; et al. Cigarette smoke and chewing tobacco alter expression of different sets of miRNAs in oral keratinocytes. Sci. Rep. 2018, 8, 1-13. [CrossRef]

42. Fazeli, S.; Motovali-Bashi, M.; Peymani, M.; Hashemi, M.-S.; Etemadifar, M.; Nasr-Esfahani, M.H.; Ghaedi, K. A compound downregulation of SRRM2 and miR-27a-3p with upregulation of miR-27b-3p in PBMCs of Parkinson's patients is associated with the early stage onset of disease. PLoS ONE 2020, 15, e0240855. [CrossRef]

43. Shafiei, J.; Heidari, F.; Khashen, E.; Ghandehari-Alavijeh, R.; Darmishonnejad, Z. Distinctive deregulation of miR-27a and miR-27b in relapsing remitting multiple sclerosis. J. Bas. Res. Med. Sci. 2020, 7, 1-6.

44. Ma, M.; Yin, Z.; Zhong, H.; Liang, T.; Guo, L. Analysis of the expression, function, and evolution of miR-27 isoforms and their responses in metabolic processes. Genomics 2019, 111, 1249-1257. [CrossRef] [PubMed]

45. Libby, P.; Ridker, P.M.; Hansson, G.K. Inflammation in Atherosclerosis. J. Am. Coll. Cardiol. 2009, 54, 2129-2138. [CrossRef]

46. Ross, R. Atherosclerosis-An Inflammatory Disease. N. Engl. J. Med. 1999, 340, 115-126. [CrossRef]

47. Kaur, A.; Mackin, S.T.; Schlosser, K.; Wong, F.L.; Elharram, M.; Delles, C.; Stewart, D.J.; Dayan, N.; Landry, T.; Pilote, L. Systematic review of microRNA biomarkers in acute coronary syndrome and stable coronary artery disease. Cardiovasc. Res. 2019, 116, 1113-1124. [CrossRef]

48. Cheng, H.S.; Sivachandran, N.; Lau, A.; Boudreau, E.; Zhao, J.L.; Baltimore, D.; Delgado-Olguin, P.; Cybulsky, M.I.; Fish, J.E. Micro RNA -146 represses endothelial activation by inhibiting pro-inflammatory pathways. EMBO Mol. Med. 2013, 5, 1017-1034. [CrossRef]

49. Wang, H.-J.; Huang-Joe, W.; Shih, Y.-Y.; Wu, H.-Y.; Peng, C.-T.; Lo, W.-Y. MicroRNA-146a Decreases High Glucose/ThrombinInduced Endothelial Inflammation by Inhibiting NAPDH Oxidase 4 Expression. Mediat. Inflamm. 2014, 2014, 1-12. [CrossRef] [PubMed]

50. Lin, X.; Zhan, J.-K.; Wang, Y.-J.; Tan, P.; Chen, Y.-Y.; Deng, H.-Q.; Liu, Y.-S. Function, Role, and Clinical Application of MicroRNAs in Vascular Aging. BioMed Res. Int. 2016, 2016, 1-15. [CrossRef] [PubMed] 
51. Li, J.; Zhao, L.; He, X.; Yang, T.; Yang, K. MiR-21 inhibits c-Ski signaling to promote the proliferation of rat vascular smooth muscle cells. Cell. Signal. 2014, 26, 724-729. [CrossRef]

52. Weber, M.; Baker, M.B.; Moore, J.P.; Searles, C.D. MiR-21 is induced in endothelial cells by shear stress and modulates apoptosis and eNOS activity. Biochem. Biophys. Res. Commun. 2010, 393, 643-648. [CrossRef]

53. Jin, C.; Zhao, Y.; Yu, L.; Xu, S.; Fu, G. MicroRNA-21 mediates the rapamycin-induced suppression of endothelial proliferation and migration. FEBS Lett. 2013, 587, 378-385. [CrossRef]

54. Zhou, J.; Wang, K.-C.; Wu, W.; Subramaniam, S.; Shyy, J.Y.-J.; Chiu, J.-J.; Li, J.Y.-S.; Chien, S. MicroRNA-21 targets peroxisome proliferators-activated receptor- in an autoregulatory loop to modulate flow-induced endothelial inflammation. Proc. Natl. Acad. Sci. USA 2011, 108, 10355-10360. [CrossRef]

55. Ulrich, V.; Rotllan, N.; Araldi, E.; Luciano, A.; Skroblin, P.; Abonnenc, M.; Perrotta, P.; Yin, X.; Bauer, A.; Leslie, K.L.; et al. Chronic miR-29 antagonism promotes favorable plaque remodeling in atherosclerotic mice. EMBO Mol. Med. 2016, 8, 643-653. [CrossRef]

56. Zhang, P.; Huang, A.; Ferruzzi, J.; Mecham, R.P.; Starcher, B.C.; Tellides, G.; Humphrey, J.D.; Giordano, F.J.; Niklason, L.E.; Sessa, W.C. Inhibition of MicroRNA-29 Enhances Elastin Levels in Cells Haploinsufficient for Elastin and in Bioengineered Vessels-Brief Report. Arter. Thromb. Vasc. Biol. 2012, 32, 756-759. [CrossRef] [PubMed]

57. Schober, A.; Nazari-Jahantigh, M.; Wei, Y.; Bidzhekov, K.; Gremse, F.; Grommes, J.; Megens, R.T.A.; Heyll, K.; Noels, H.; Hristov, M.; et al. MicroRNA-126-5p promotes endothelial proliferation and limits atherosclerosis by suppressing Dlk1. Nat. Med. 2014, 20, 368-376. [CrossRef]

58. Kumar, S.; Kim, C.W.; Simmons, R.D.; Jo, H. Role of Flow-Sensitive microRNAs in Endothelial Dysfunction and Atherosclerosis. Arter. Thromb. Vasc. Biol. 2014, 34, 2206-2216. [CrossRef] [PubMed]

59. Fernández-Hernando, C.; Suárez, Y. MicroRNAs in endothelial cell homeostasis and vascular disease. Curr. Opin. Hematol. 2018, 25, 227-236. [CrossRef]

60. Small, E.M.; Sutherland, L.B.; Rajagopalan, K.N.; Wang, S.; Olson, E.N. MicroRNA-218 Regulates Vascular Patterning by Modulation of Slit-Robo Signaling. Circ. Res. 2010, 107, 1336-1344. [CrossRef]

61. Huang, R.S.; Gamazon, E.R.; Ziliak, D.; Wen, Y.; Im, H.K.; Zhang, W.; Wing, C.; Duan, S.; Bleibel, W.K.; Cox, N.J.; et al. Population differences in microRNA expression and biological implications. RNA Biol. 2011, 8, 692-701. [CrossRef] [PubMed]

62. Rawlings-Goss, R.A.; Campbell, M.C.; Tishkoff, S.A. Global population-specific variation in miRNA associated with cancer risk and clinical biomarkers. BMC Med. Genom. 2014, 7, 53. [CrossRef] 